\title{
BIOHYDROGEN PRODUCTION FROM SWEET SORGHUM BIOMASS USING MIXED ACIDOGENIC CULTURES AND PURE CULTURES OF RUMINOCOCCUS ALBUS
}

\author{
G. ANTONOPOULOU ${ }^{1}$ \\ I. NTAIKOU ${ }^{1}$ \\ H.N. GAVALA ${ }^{1, *}$ \\ I.V. SKIADAS ${ }^{1}$ \\ K. ANGELOPOULOS ${ }^{2}$ \\ G. LYBERATOS ${ }^{1}$
}

Received: 19/09/06

Accepted: 15/01/07
${ }^{1}$ Department of Chemical Engineering,

University of Patras, Karatheodori 1 st. 26500 Patras, Greece

${ }^{2}$ Department of Biology, University of Patras, 26500 Patras, Greece

*to whom all correspondence should be addressed: e-mail: gavala@chemeng.upatras.gr

\begin{abstract}
The present study focuses on the exploitation of sweet sorghum biomass as a source for hydrogen in continuous and batch systems. Sweet sorghum is an annual C4 plant of tropical origin, well-adapted to sub-tropical and temperate regions and highly productive in biomass. Sweet sorghum biomass is rich in readily fermentable sugars and thus it can be considered as an excellent raw material for fermentative hydrogen production. Extraction of free sugars from the sorghum stalks was achieved using water at $30^{\circ} \mathrm{C}$. After the extraction process, a liquid fraction (sorghum extract), rich in sucrose, and a solid fraction (sorghum cellulosichemicellulosic residues), containing the cellulose and hemicelluloses, were obtained. Hydrogen production from sorghum extract was investigated using mixed acidogenic microbial cultures, coming from the indigenous sorghum microflora and Ruminococcus albus, an important, fibrolytic bacterium of the rumen. Hydrogen productivity of sorghum residues was assessed as well, using $R$. albus.

The highest hydrogen yield obtained from sorghum extract fermented with mixed microbial cultures in continuous system was 0.86 mol hydrogen per mol of glucose consumed, at a hydraulic retention time of 12 hours. This corresponded to a hydrogen productivity of 10.4 I hydrogen per $\mathrm{kg}$ of sorghum biomass and was comparable with those obtained from batch experiments. On the other hand, the hydrogen yield obtained from sorghum extract treated with $R$. albus was as high as 2.1-2.6 mol hydrogen per mol of glucose consumed. Hydrogen productivity of sorghum residues fermented with $R$. albus reached 2.6 mol hydrogen per mol of glucose consumed. In total, the productivity of sorghum biomass (that of sorghum extract plus that of sorghum residues) could be 60 I hydrogen per $\mathrm{kg}$ of sorghum biomass if $R$. albus is used.
\end{abstract}

KEYWORDS: biofuels, biomass, fermentation, hydrogen, mixed microbial cultures, sweet sorghum, Ruminococcus albus

\section{INTRODUCTION}

The world population and consequently energy demands seem to grow following an exponential rate (Nakicenovich, 1998). The impending shortage of energy resources together with the environmental fall off, due to unreasonable use of fossil fuels, lead many scientists to the search for alternative energy sources. Among others, research has focused on hydrogen production field, either by physicochemical or biological methods. Hydrogen is a clean and environmentally friendly fuel, which produces water instead of greenhouse gases when combusted. It can be produced by renewable raw materials, such as organic wastes, and possesses a high-energy yield $\left(122 \mathrm{~kJ} \mathrm{~g}^{-1}\right)$ due to its light weight. Furthermore, hydrogen 
could be directly used to produce electricity through fuel cells (Lay et al., 1999; Benemann, 1996). One of the main drawbacks of hydrogen use is the difficulty of securing a safe storage, especially in automobiles. However, this problem could be overcome by the use of metal hydrides and carbon nanotubes, which reversibly adsorb hydrogen at room temperature and low pressures (Ramachandran and Menon 1988; Noike and Mizuno, 2000; Ajayan and Zhou, 2001).

Biological hydrogen production has received special attention during the last decade. Biohydrogen may be produced by cyanobacteria and algae through biophotolysis of water (Asada and Miyaka, 1999) or by photosynthetic and chemosynthetic - fermentative bacteria. Anaerobic fermentative bacteria produce hydrogen without photoenergy, and so the cost of hydrogen production is 340 times lower than the photosynthetic process (Morimoto, 2002).

The main source of hydrogen during a biological, fermentative process is carbohydrates, which are very common in plant tissues, either in the form of oligosaccharides or as their polymers, cellulose, hemicellulose and starch. Thus, the biomass of certain plants with high content in carbohydrates could be considered as a very promising substrate for biohydrogen production. Such plants are misckanthus, sugarcane and sorghum, the so-called energy crops. In addition, using properly selected microorganisms, many rural residues can be exploited for hydrogen production as well. The maximum theoretical hydrogen yield is 4 moles per mole of utilized carbohydrates, expressed as glucose equivalents when carbohydrates are used as substrate (Nandi and Sengupta, 1998).

Sweet sorghum (Sorghum bicolor (L.) Moench) is an annual C4 plant of tropical origin, welladapted to sub-tropical and temperate regions and highly productive in biomass. Sweet sorghum stalks are rich in sugars, mainly in sucrose that amounts up to $55 \%$ of dry matter and in glucose $(3.2 \%$ of dry matter). They also contain cellulose $(12.4 \%)$ and hemicelluloses $(10.2 \%)$ (Billa et al., 1997). Sweet sorghum biomass is rich in readily fermentable sugars and thus it can be considered as an excellent raw material for fermentative hydrogen production. Overall, out of many "new crops" that are currently investigated as potential raw materials for energy and industry, sweet sorghum seems to be the most promising one (Dalianis et al., 1996; Gosse, 1996). Although sorghum has been thoroughly investigated as an energy crop for bioethanol and methane production (Jackman, 1987; Richards et al., 1991; Mamma et al., 1996), it has not been used so far as a potential source for hydrogen production. Sorghum biomass could be fully exploited for hydrogen production since both soluble and complex carbohydrates can be utilized, either in a single step or separately after extraction. Extraction of free sugars from the stalks is easily achieved using water at $30^{\circ} \mathrm{C}$. After the extraction process a liquid fraction (sorghum extract), rich in sucrose, and a solid fraction (sorghum cellulosic-hemicellulosic residues), containing the cellulose and hemicelluloses, are obtained.

Fermentative hydrogen production from biomass can be achieved either by using mixed acidogenic microbial cultures or a pure culture of a saccharolytic strain. Ruminococcus albus is a non spore-forming, obligatory anaerobic, coccoid bacterium (Hungatte, 1966; Bryant, 1959), the natural habitat of which is the first stomach (rumen) of the ruminants. It produces extracellular hydrolytic enzymes (exoglucanases and endoglucanases), which break down cellulose (Ohmiya et al., 1985, Ohmiya et al., 1987, Ohmiya et al., 1988) and hemicellulose (Dehority, 1973), whereas it can not break down pectin and starch (Hungate, 1960). The oligosaccharides produced from cellulose and hemicellulose degradation - cellobiose, glucose and the respective pentoses xylose and arabinose, are further metabolised (Lou et al., 1997, Thurston et al., 1994).

The present study focuses on the exploitation of sweet sorghum biomass as a source for hydrogen in continuous and batch systems. Hydrogen production from sorghum extract was investigated using mixed acidogenic microbial cultures coming from the indigenous sorghum microflora and Ruminococcus albus. Hydrogen productivity of sorghum residues was assessed as well using the fibrolytic bacterium $R$. albus. 


\section{MATERIALS AND METHODS}

\subsection{Sweet sorghum biomass}

The sweet sorghum biomass (Sorghum bicolor L. Moench) used in the present study was produced in field experiments at the University of Patras experimental station. Sweet sorghum var. Keller seeds were sown at mid of May and the stalks were harvested at mid of October. After the harvesting of sorghum stalks, the fresh stems were stripped from the leaves, were chopped to a size of $20 \mathrm{~cm}$ and were stored in the freezer at $-20^{\circ} \mathrm{C}$. Subsequently, the stalks were milled by a laboratory grinder to an average particle size of 1-2 mm. Extraction of free sugars of the sorghum biomass was done in batches, by mixing $5 \mathrm{~kg}$ of milled sorghum stalks with $30 \mathrm{~L}$ of tap water for $1 \mathrm{~h}$, at $30^{\circ} \mathrm{C}$. After the extraction process a liquid fraction (sorghum extract), rich in soluble carbohydrates and a solid fraction (sorghum cellulosic-hemicellulosic residues) were obtained. Sorghum extract and residues were preserved at $-20^{\circ} \mathrm{C}$ and used as substrate for hydrogen production by mixed acidogenic cultures and pure cultures of $R$. albus.

\subsection{Experiments with mixed acidogenic cultures}

\subsubsection{Continuous experiments}

A $500 \mathrm{ml}$ active volume mesophilic $\left(35^{\circ} \mathrm{C}\right)$ CSTR-type digester was started-up and fed with sorghum extract. The reactor was cylindrical in shape, made of stainless steel and stirred periodically for $15 \mathrm{~min}, 2$ times per hour. For start-up, the reactor was filled up with sorghum extract, operated anaerobically at a batch mode for $24 \mathrm{~h}$ in order to activate the indigenous microflora and was subsequently switched to the continuous mode at the designated HRT. The reactor was operated anaerobically at hydraulic retention times (HRT) of 24, 12, 8, 6 and $4 \mathrm{~h}$ and fed intermittently with sorghum extract maintained at a temperature below $4^{\circ} \mathrm{C}$ for 1 , 2, 3, 4 and 6 min, respectively, every 3 hours. Feeding was programmed always with the stirring on. Simultaneous flow of the effluent occurred during feeding by liquid overflow, in order to maintain constant reactor volume.

$2.24 \mathrm{~g} \mathrm{NaOH}$ and $6.8025 \mathrm{~g} \mathrm{KH}_{2} \mathrm{PO}_{4}$ per liter of sorghum extract were added in order to maintain the $\mathrm{pH}$ of the $\mathrm{H}_{2}$-CSTR at levels (4.7-5.5) allowing for hydrogen production. Also $2 \mathrm{~g}$ urea $\left(\mathrm{NH}_{2} \mathrm{CONH}_{2}\right)$ per liter of sorghum extract was added to make up for $\mathrm{N}$ deficiency of the feed. Gas and liquid samples were taken $10-15$ minutes before feeding started. The reactor performance (biogas production and composition in $\mathrm{H}_{2}, \mathrm{pH}$ and carbohydrates influent and effluent concentration) was monitored daily throughout the experimental period and the reactor was operated at each HRT until a steady state was reached. Steady-state here meant constant conditions between successive feeding cycles.

\subsubsection{Batch experiments}

Four batch experiments took place in vials of $1350 \mathrm{ml}$ total volume sealed with rubber stoppers. $300 \mathrm{ml}$ of the continuous reactor effluent at the steady states of $12,8,6$ and $4 \mathrm{~h}$ was used as inoculum and mixed with $150 \mathrm{ml}$ of sorghum extract. The hydrogen evolution was followed versus time and carbohydrates concentration was determined at the start and end of the experiments.

\subsection{Experiments with pure cultures of Ruminococcus albus 2.3.1.Organism, medium and growth conditions}

R. albus, strain DSMZ 20455 (Bryant et al., 1958, Skerman et al., 1980) was obtained from the Deutsche Sammlung von Microorganismen und Zellkulturen (DSMZ) culture collection and was maintained in a modified DSMZ 453 medium of the following composition: $5 \mathrm{~g} \mathrm{I}^{-1}$ glucose, $5 \mathrm{~g} \mathrm{l}^{-1}$ tryptone, $2 \mathrm{~g} \mathrm{l}^{-1}$ yeast extract, $20.6 \mathrm{~g} \mathrm{l}^{-1} \mathrm{KH}_{2} \mathrm{PO}_{4}, 4.6 \mathrm{~g} \mathrm{l}^{-1} \mathrm{~K}_{2} \mathrm{HPO}_{4}, 0.48 \mathrm{~g} \mathrm{l}^{-1}$ $\mathrm{NaCl}, 0.8 \mathrm{~g} \mathrm{l}^{-1}\left(\mathrm{NH}_{4}\right)_{2} \mathrm{SO}_{4}, 0.1 \mathrm{~g} \mathrm{I}^{-1} \mathrm{MgSO}_{4} \cdot 7 \mathrm{H}_{2} \mathrm{O}, 0.03695 \mathrm{~g} \mathrm{l}^{-1} \mathrm{CaCl}_{2} \cdot 2 \mathrm{H}_{2} \mathrm{O}, 4 \mathrm{gl}^{-1} \mathrm{Na}_{2} \mathrm{CO}_{3}, 0.5$ $\mathrm{g} \mathrm{I}^{-1}$ cystein- $\mathrm{HCl}, 0.1 \mathrm{ml} \mathrm{I}^{-1}$ isovaleric acid, $0.1 \mathrm{ml} \mathrm{l}^{-1}$ isobutyric acid and $0.1 \mathrm{ml} \mathrm{l}^{-1}$ methylbutyric acid. The medium containing the organic compounds, the salts solutions, the acids mixture and the cystein- $\mathrm{HCl}$ solution were sterilized separately at $121^{\circ} \mathrm{C}$ for 20 minutes, cooled down and mixed anaerobically under sterile conditions. Stock cultures were stored at $-22^{\circ} \mathrm{C}$ in $20 \%$ glycerol and inoculation cultures were transferred twice before use. The basal medium was used in all cultures while the carbon source was varied depending on the substrate tested, i.e. 
glucose, whole sorghum stalks, sorghum extract and sorghum cellulosic-hemicellulosic residues. All cultures were grown in a $\mathrm{CO}_{2} / \mathrm{N}_{2}$ atmosphere, at $37 \pm 1^{\circ} \mathrm{C}$ and continuous stirring of $200 \pm 10 \mathrm{rpm}$.

\subsubsection{Continuous experiment}

Continuous experiment was performed in a 2.5 I Virtis Omni-culture bench-top chemostat with working volume of $1320 \mathrm{ml}$ and headspace of $1630 \mathrm{ml}$ (Figure 1). Sterilized sorghum extract was continuously supplied to the chemostat using a peristaltic pump at a hydraulic retention time (HRT) of 42 hours. The temperature of the culture medium in the chemostat was automatically controlled at $37 \pm 1^{\circ} \mathrm{C}$ through warm water recirculation from a water bath. A trap was used between the chemostat and the effluent bottle, in order to prevent back mixing of the gas phases. The reactor performance (biogas production and composition in $\mathrm{H}_{2}, \mathrm{pH}$ and carbohydrates influent and effluent concentration) was monitored daily throughout the experimental period until a steady state was reached.

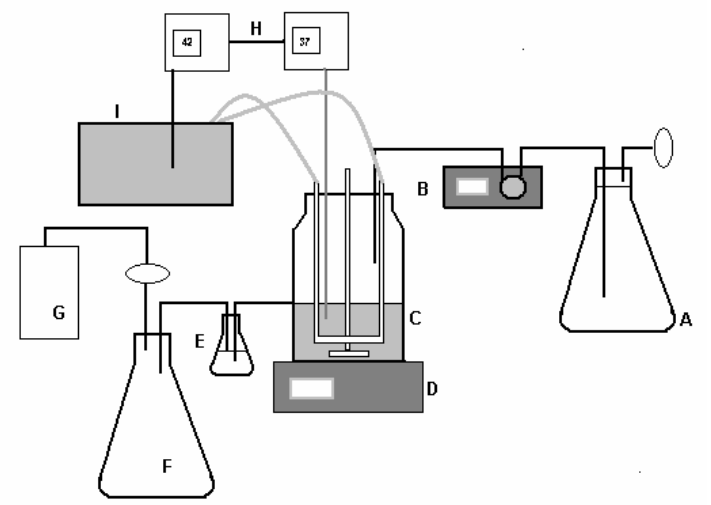

Figure 1. Continuous culture apparatus: A. Influent reservoir, B. Peristaltic pump, C.

Chemostat, D. Magnetic stirrer, E. Gas trap, F. Effluent collection bottle, G. Gas collection balloon, $\mathrm{H}$. Temperature controller, I. Water bath

\subsubsection{Batch experiments}

Two series of batch experiments took place in serum vials of $161 \mathrm{ml}$ total volume sealed with rubber stoppers and aluminum crimps. The first series consisted of four batches in duplicates with different initial concentration of carbohydrates in order to investigate any inhibition effect of the substrate concentration. The ratio of culture volume and headspace were adjusted so as the final partial pressure of hydrogen be approximately the same. The hydrogen evolution was followed versus time and carbohydrates concentration was determined at the start and end of the experiments.

The second series consisted of four batches in duplicates with glucose, sorghum extract, sorghum stalks and lignocellulosic sorghum residues with same initial concentration of carbohydrates expressed as glucose equivalents. The hydrogen evolution was followed versus time and carbohydrates concentration was determined at the start and end of the experiments.

\subsection{Analytical methods}

The produced gas composition in hydrogen was quantified using a gas chromatograph (VARIAN STAR 3600) equipped with a thermal conductivity detector and a packed column with nitrogen as carrier gas. The injector, column and detector temperatures were set at $70^{\circ} \mathrm{C}$, $80^{\circ} \mathrm{C}$ and $180^{\circ} \mathrm{C}$ respectively. The measurement of the produced gas volume during the continuous experiments was based on the displacement of acidified water. For total and soluble (following centrifugation and filtration of the supernatant) carbohydrates determination, a colored sugar derivative was produced through the addition of L-tryptophan, sulphuric and boric acid (Eberlein and Schutt, 1986, Josefsson, 1983), which was subsequently measured colorimetrically at $520 \mathrm{~nm}$. 


\section{RESULTS AND DISCUSSION}

\subsection{Continuous experiments with mixed acidogenic cultures}

No traces of methane were detected during the operation of the CSTR-type digester with mixed acidogenic culture at all retention times. In table 1 the biogas content in hydrogen, hydrogen production rates and hydrogen yields are presented for each steady state. The hydrogen production rate systematically increased, when the HRT was decreased from 24 to $6 \mathrm{~h}$, where the higher hydrogen production rate was obtained $\left(2550 \pm 90 \mathrm{ml} \mathrm{H}_{2} \mathrm{~d}^{-1}\right)$. Further decrease of the HRT to $4 \mathrm{~d}$ led to a reduction of the hydrogen production rates. In general, the biogas composition in hydrogen always lied between 30 and $40 \%$ and was higher $(40 \%)$ for the HRTs of 12,8 , and $6 \mathrm{~h}$ compared to those at 24 and $4 \mathrm{~h}$ ( 30 and $35 \%$ respectively). Moreover, the yield of hydrogen produced per mole of glucose consumed and, consequently, that of hydrogen produced per $\mathrm{kg}$ of sweet sorghum as well, reached the highest value at the HRT of 8h, amounting up to $0.86 \pm 0.04 \mathrm{~mol} \mathrm{H}_{2} \mathrm{~mol}^{-1}$ glucose consumed and $10.4 \mathrm{I} \mathrm{H}_{2} \mathrm{~kg}^{-1}$ sweet sorghum, respectively. In general, the hydrogen yield was within the range of 0.37-0.86 $\mathrm{mol} \mathrm{H}_{2}$ mol $^{-1}$ glucose consumed.

At this point it should be emphasized that the start-up of the reactor was made with indigenous sweet sorghum microflora without heat treatment, which generally favors the spore-forming, hydrogen-producing clostridia. The fact that the sorghum microflora can be used for the production of hydrogen is important for the operation of a full-scale plant suggesting that no extra energy will be required neither for the start-up (heat treatment) of the reactor nor for the pasteurization or sterilization of the influent. Based on the above observations on the hydrogen yield and the production rate, the optimal HRT seems to be between 12 - 6 hours (Antonopoulou et al., 2006).

Table 1. Biogas and hydrogen production rates and hydrogen yields in the CSTR-type digester with mixed acidogenic culture at steady state accompanied by their standard deviation.

\begin{tabular}{|c|c|c|c|c|}
\hline HRT, h & $\begin{array}{c}\text { Biogas } \\
\text { content in } \mathrm{H}_{2} \\
\%\end{array}$ & $\begin{array}{c}\text { Hydrogen } \\
\text { production rate, } \\
\mathrm{ml} \mathrm{d}^{-1}\end{array}$ & $\begin{array}{l}\text { Hydrogen yield, } \\
\text { mol H}_{2} \text { mol }^{-1} \\
\text { glucose }\end{array}$ & 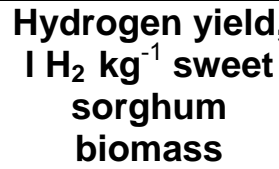 \\
\hline 24 & $30.4 \pm 1.2$ & $410 \pm 40$ & $0.37 \pm 0.02$ & 4.9 \\
\hline 12 & $39.9 \pm 1.2$ & $1740 \pm 100$ & $0.86 \pm 0.04$ & 10.4 \\
\hline 8 & $40.5 \pm 1.9$ & $2070 \pm 120$ & $0.75 \pm 0.05$ & 8.4 \\
\hline 6 & $39.2 \pm 0.5$ & $2550 \pm 90$ & $0.70 \pm 0.02$ & 7.6 \\
\hline 4 & $35.0 \pm 1.5$ & $2180 \pm 150$ & $0.41 \pm 0.02$ & 4.3 \\
\hline
\end{tabular}

\subsection{Batch experiments with mixed acidogenic cultures}

In table 2 the hydrogen yields are presented for each batch experiment with mixed acidogenic culture coming from different steady states as inoculum and sorghum extract as substrate. Hydrogen yields expressed as $\mathrm{mol} \mathrm{H}_{2}$ per mol of glucose consumed are comparable with these obtained from the CSTR-type digester. Differences in hydrogen yields expressed as I $\mathrm{H}_{2}$ per $\mathrm{kg}$ of sorghum biomass (tables 1 and 2) are attributed to the intermittent reactor feeding pattern with the more affected being the one related to the steady state at $4 \mathrm{~h}$ HRT. Obviously at a full-scale plant where a continuous feeding is applied that difference would be minimal. Consequently, hydrogen yield from sorghum extract treated with mixed acidogenic culture could reach $11.2 \mathrm{I} \mathrm{H}_{2}$ per $\mathrm{kg}$ of sweet sorghum biomass.

\subsection{Continuous experiment with pure cultures of $R$. albus}

Continuous experiments with pure cultures of Ruminococcus albus fed with sorghum extract at an HRT of $42 \mathrm{~h}$ resulted at a hydrogen yield of $1 \mathrm{~mol}$ per mol of glucose consumed. This corresponds to a productivity of $9.1 \mathrm{I} \mathrm{H}_{2}$ per $\mathrm{Kg}$ of sorghum biomass. The biogas content in hydrogen was $53 \%$. 
Table 2. Hydrogen yield in batch experiments with mixed acidogenic culture coming from different steady states and sorghum extract as inoculum and substrate respectively

\begin{tabular}{lcc}
\hline $\begin{array}{l}\text { Inoculum coming from } \\
\text { CSTR steady state } \\
\text { HRT, } \mathbf{h}\end{array}$ & $\begin{array}{c}\text { Hydrogen yield, } \\
\mathbf{m o l ~ H}_{\mathbf{2}} \mathbf{~ m o l}^{-1} \text { glucose }\end{array}$ & $\begin{array}{c}\text { Hydrogen yield, } \\
\mathbf{I} \mathbf{~ H}_{\mathbf{2}} \mathbf{k g}^{-1} \\
\text { sweet sorghum } \\
\text { biomass }\end{array}$ \\
\hline 12 & 0.75 & 11.16 \\
8 & 0.786 & 8.76 \\
6 & 0.648 & 6.26 \\
4 & 0.53 & 8.1 \\
\hline
\end{tabular}

\subsection{Batch experiments with pure culture of $R$. albus}

In table 3 the hydrogen yields are presented for each batch experiment with pure culture of $R$. albus and different initial glucose concentration. All experiments gave a high hydrogen yield of approximately $2 \mathrm{~mol}$ per mol of glucose consumed. Therefore, initial glucose concentration at the range of $5-20 \mathrm{~g} \mathrm{I}^{-1}$ had no effect on the hydrogen yield. In table 4 the results from the second series of batch experiments are shown. In all cases hydrogen yields were high and lied between 2.5-3.2 mol $\mathrm{H}_{2}$ per mol of glucose consumed. It is noticeable that hydrogen yields in batch experiments with $R$. albus were double than that obtained from the chemostat (§ 3.3). This could be attributed to the incomplete breakdown of formic acid in the chemostat, which the hydrogen mainly comes from during the catabolism of hexoses from R. albus (Ntaikou et al., 2006). Operating the chemostat at higher hydraulic retention times would allow for complete formic acid breakdown and most probably result to higher hydrogen yields. In table 5 the hydrogen productivity expressed in $\mathrm{I}_{2}$ per $\mathrm{Kg}$ of sorghum biomass from both sorghum extract and sorghum residues (obtained after the extraction process) is shown. It is obvious that use of $R$. albus resulted not only to increased hydrogen yield from sorghum extract compared to that obtained from mixed acidogenic culture but also to the possibility of sorghum residues exploitation for hydrogen production. In total the hydrogen productivity could reach approximately $60 \mathrm{I} \mathrm{H}_{2}$ per $\mathrm{Kg}$ of sorghum biomass. The drawback of using a pure microbial culture as $R$. albus for hydrogen production from sorghum biomass compared to the use of the mixed indigenous acidogenic culture is the necessity for maintaining sterilized conditions with consequent extra energy requirements.

Table 3. Hydrogen yields from batch cultures of $R$. albus on sorghum extract with different initial carbohydrates concentration

\begin{tabular}{ccc}
\hline $\begin{array}{c}\text { Initial concentration of } \\
\text { carbohydrates, } \mathrm{g} \mathrm{I}^{-1}\end{array}$ & Hydrogen yield, mol mol & \\
\hline 5 & $2.09 \pm 0.07$ & $\mathrm{P}_{\mathrm{H} 2}$ final, bar \\
10 & $2.12 \pm 0.09$ & $0.81 \pm 0.03$ \\
15 & $2.11 \pm 0.05$ & $0.77 \pm 0.05$ \\
20 & $2.14 \pm 0.01$ & $0.77 \pm 0.03$ \\
\hline
\end{tabular}

Table 4. Hydrogen yields from batch cultures of $R$. albus on glucose, sorghum extract, sorghum stalks and sorghum residues with initial concentrations of $3 \mathrm{~g} \mathrm{I}^{-1}$ carbohydrates measured as glucose equivalents

\begin{tabular}{lcc}
\hline Carbon source & Hydrogen yield, mol mol & -1 \\
glucose & $\mathrm{P}_{\mathrm{H} 2}$ final, bar \\
\hline slucose & $2.52 \pm 0.09$ & $0.95 \pm 0.02$ \\
sorghum extract & $2.61 \pm 0.08$ & $0.89 \pm 0.04$ \\
sorghum stalks & $3.15 \pm 0.03$ & $0.82 \pm 0.01$ \\
\hline
\end{tabular}

\section{CONCLUSIONS}

In the present study, hydrogen production from sorghum extract was investigated using mixed acidogenic microbial cultures coming from the indigenous sorghum microflora and Ruminococcus albus, an important, fibrolytic bacterium of the rumen. Hydrogen productivity of sorghum residues was assessed as well using $R$. albus. 
Table 5. Calculated hydrogen productivities per mass unit of sorghum biomass (humidity

\begin{tabular}{|c|c|c|}
\hline \multirow{3}{*}{$\begin{array}{l}\text { Whole sorghum } \\
\text { Sorghum extract } \\
\text { Sorghum residues }\end{array}$} & \multicolumn{2}{|c|}{$\begin{array}{c}\text { Productivity } \\
\mathrm{L} \mathrm{H}_{2} \mathrm{~kg}^{-1} \text { wet sorghum biomass }\end{array}$} \\
\hline & & \\
\hline & $\begin{array}{l}28 \\
31\end{array}$ & 59 (total) \\
\hline
\end{tabular}

The highest hydrogen yield obtained from sorghum extract fermented with mixed microbial cultures in continuous system was 0.86 mol hydrogen per mol of glucose consumed at the hydraulic retention time of 12 hours. This corresponded to a hydrogen productivity of 10.4 I hydrogen per $\mathrm{kg}$ of sorghum biomass and was comparable with those obtained from batch experiments. On the other hand, the hydrogen yield obtained from sorghum extract treated with $R$. albus was as high as 2.1-2.6 mol hydrogen per mol of glucose consumed. Hydrogen productivity of sorghum residues fermented with $R$. albus reached 2.6 mol hydrogen per mol of glucose consumed. In total, the productivity of sorghum biomass (that of sorghum extract plus that of sorghum residues) could be $60 \mathrm{I}$ hydrogen per $\mathrm{kg}$ of sorghum biomass if $R$. albus is used.

It is obvious that use of $R$. albus resulted not only to increased hydrogen yield from sorghum extract compared to that obtained from mixed acidogenic culture but also to the possibility of sorghum residues exploitation for hydrogen production. However, the drawback of using a pure microbial culture for hydrogen production from sorghum biomass compared to the use of the mixed indigenous acidogenic culture is the necessity for maintaining sterilized conditions with consequent extra energy requirements, unless $R$. albus can indeed proliferate under nonsterile conditions. Whether this is possible, need to be examined, however.

\section{ACKNOWLEDGEMENTS}

The authors wish to thank the Hellenic General Secretariat for Research and Technology for the financial support of this work under "PENED 2001, 01ED390".

\section{REFERENCES}

Ajayan P.M. and Zhou O.Z., (2001), Applications of carbon nanotubes, Topics Appl. Phys., 80, 391-425.

Antonopoulou G., Gavala H.N., Skiadas I.V., Angelopoulos K. and Lyberatos G., (2006), Biofuels generation from sweet sorghum: fermentative hydrogen production and anaerobic digestion of the remaining biomass, Bioresource Technology (submitted)

Asada Y., Miyake J., (1999), Photobiological hydrogen production, J Biosci Bioeng, 88(1), 1-6.

Benemann J., (1996), Hydrogen biotechnology : progress and prospects, Nature Biotechnol., 14(9), 1101-1103.

Billa E., Koullas D.P., Monties B. and Koukios E.G., (1997), Structure and composition of sweet sorghum stalk components, Industrial Crops and Products, 6, 297-302.

Bryant M.P., Small N. Bouma C. and. Robinson I.M., (1958), Characteristics of ruminal anaerobic cellulolytic cocci and Cillobacterium cellulosolvens n. sp., J Bacteriol, 76, 529-537.

Bryant M.P., (1959), Bacterial species of the rumen, Bacteriol. Rev., 23, 125-153.

Jackman, E. A. (1987), In Basic Biotechnology, In: ........(title) by Bu Lock J., Kristiansen, B. (Eds), Academic Press, pp. 309-336.

Dalianis C., Panoutsou C. Dercas N., (1996) Sweet and fiber sorghum, two promising biomass crops, In: First European Seminar on Sorghum for Energy and Industry, Toulouse, France, 1-3 April, pp. 173-176.

Dehority B.A., (1973), Hemicellulose degradation by rumen bacteria, Fed Proc, 32, 1819-1825.

Eberlein K and Schutt M. (1986) Automatic methods for the determination of total dissolved and particulate carbohydrates in the marine environment, Anal Bioanal Chem., 323, 47-49. 
Gosse G. (1996) Overview on the different routes for industrial utilization of sorghum, in: Abstracts book, First European Seminar on Sorghum for energy and Industry, Toulouse, France, 1-3 April, pp.2.

Hungate R.E. (1960) Microbial ecology of the rumen, Bacteriol Rev, 24(4), 353-364.

Hungate R.E. (1966) The rumen and its microbes, Academic Press, Inc.,New York, N.Y.

Josefsson B. (1983) Rapid spectrophotometric determination of total carbohydrates, In: Methods of seawater analysis, by K. Grasshoff, M. Ehrhardt and K. Kremling (eds), Verlag Chemie $\mathrm{GmbH}, 340-342$.

Lay J.J., Lee Y.J., Noike T. (1999) Feasibility of biological hydrogen production from organic fraction of municipal solid waste, Water Res., 33(11), 2579-2586.

Lou J, Dawson K.A. and Strobel H.J. (1997) Cellobiose and Cellodextrin Metabolism by the Ruminal Bacterium Ruminococcus albus, Current Microbiology, 35, 221-227.

Mamma D., Koullas D., Fountoukidis G., Kekos D., Macris B.J., Koukios E. (1996) Bioethanol from sweet sorghum: Simultaneous saccharification and fermentation of carbohydrates by a mixed microbial culture, Process biochemistry, 31(4), 377-381.

Morimoto M. (2002) Why is the anaerobic fermentation in the production of the biohydrogen attractive, In: The proceedings of conversion of biomass into bioenergy. Organized by New energy and Industrial Technology Development Organization (NEPO), Japan and Malaysian Palm oil Board (MPOP).

Nakicenovic N. (1998) Energy perspectives for Eurasia and the Kioto Protocol, IIASA Interium Report IR-98-67I.

Nandi R. and Sengupta S. (1998) Microbial production of hydrogen: an overview, Critl Rev Microb, 24, 61-84.

Noike T., Mizuno O. (2000) Hydrogen fermentation of organic municipal wastes, Water Science and Technology, 42(12), 155-162.

Ntaikou I, Gavala H.N. and Lyberatos G. (2006) Effect of hydrogen partial pressure on the formic acid yield and degradation rate during growth of the hydrogen producing bacterium Ruminococcus albus, Proceedings of the Protection and Restoration of the Environment VIII conference, July 3-7, Chania, Greece.

Ohmiya K, Shiral M, Kurac Y, Shimizu S. (1985) Isolation and properties of b-glucosidase from Ruminococcus albus, J Bacteriol, 161, 432-439.

Ohmiya K, Maeda K, Shimizu S. (1987) Purification and properties of endo-b-1,4-glucanase from Ruminococcus albus, Carbohydr Res, 166, 145-155.

Ohmiya K, Nagashima K, Kajino T, Goto E, Tsukada A, Schimizu S. (1988) Cloning of the cellulase gene from Ruminococcus albus and its expression in Escherichia coli, Appl Environ Microbiol, 54, 1511-1555.

Ramachandran R., Menon, R.K. (1998) An overview of industrial uses of hydrogen, Int J Hydrogen Energy. 23(7), 593-598.

Richards, B.K., Cummings, R.J., Jewell, W.J. (1991) High rate low solids methane fermentation of sorghum, corn and cellulose, Biomass and Bioenergy, 1(5), 249-260.

Skerman V.B.D., Mc-Gowan V. and Sneath P.H.A. (1980) Approved list of bacterial names, Int J Syst Bacteriol, 30, 225-420.

Thurston B, Dawson K.A. and Strobel H.J. (1994) Pentoze utilization by the ruminal bacterium Ruminococcus albus, Appl. Env. Microbiol, 60, 1087-1092. 